\section{General medicine and surgery for dental practitioners. Part 5 - psychiatry}

\author{
S. Brown, ${ }^{1}$ M. Greenwood ${ }^{2}$ and J. G. Meechan ${ }^{3}$
}

IN BRIEF

- Mental illness is a common problem and can present in many ways.

- Psychiatric problems may not always be relevant to a patient's dental management, but a little knowledge may avoid problems.

- It is important to presume all patients have capacity to consent unless proven otherwise.

- Mental illness may affect dental professionals and it is important to know how to access help.

There are a significant number of patients in society who have some form of psychiatric disorder. It is important that dental practitioners have an awareness of the more common psychiatric disorders and their potential implications as they are likely to encounter them in clinical practice.

\section{INTRODUCTION}

Mental illness is common, affecting up to one in four people in the UK at some time in their lives. ${ }^{1}$ It is thus highly likely that a dentist will encounter psychiatric problems in their personal and/or professional lives.

Psychiatric problems may present to the dentist in a number of ways. The oral problem may be incidental or part of the psychiatric symptomatology. Pure dental anxiety may influence management. Thus it is important that dentists have some understanding of the basic concepts of psychiatry and the nature of psychiatric disorders.

The dentist may encounter mental health problems in relation to one of the following:

\section{GENERAL MEDICINE AND SURGERY FOR DENTAL PRACTITIONERS \\ 1. The older patient \\ 2. Metabolic disorders \\ 3. Skin disorders (A) \\ 4. Skin disorders (B) \\ 5. Psychiatry \\ 6. Cancer, radiotherapy and chemotherapy}

${ }^{1}$ Consultant Psychiatrist: ${ }^{2 *}$ Consultant/Honorary Clinical Professor, Oral and Maxillofacial Surgery, ${ }^{3}$ Honorary Consultant/Senior Lecturer in Oral and Maxillofacial Surgery, School of Dental Sciences, Newcastle University, Framlington Place, Newcastle upon Tyne, NE2 4BW *Correspondence to: Professor Mark Greenwood Email: mark.greenwood@newcastle.ac.uk

\section{Refereed Paper}

Accepted 17 February 2010

DOI: $10.1038 /$ sj.bdj.2010.578

British Dental Journal 2010; 209: 11-16
1. The underlying psychiatric condition, for example anxiety disorder, is exacerbated by the visit to the dentist, or creates problems in management

2. A psychiatric illness may be detected by the dentist, for example psychogenic pain, eating disorders, substance abuse and occasionally psychosis

3. Dental complications of psychiatric illness, for example pain syndromes, bruxism, poor oral hygiene

4. The illness may be unrelated to the dental attendance but some understanding may be useful to aid management, for example dementia, learning disability, or in relation to medication

5. The dental professional may be affected by a mental illness, most commonly alcohol problems, depression.

This paper provides an overview of how psychiatric symptoms might present to the dentist with a brief description of some common psychiatric syndromes (Table 1). Consent with reference to the Mental Capacity Act (2005) is briefly discussed, concluding with how to access support and advice from psychiatric services when required.

\section{THE UNDERLYING PSYCHIATRIC CONDITION IS EXACERBATED BY A VISIT TO THE DENTIST, OR CREATES PROBLEMS IN THE CONSULTATION}

In this scenario the dentist may or may not be aware of the underlying psychiatric

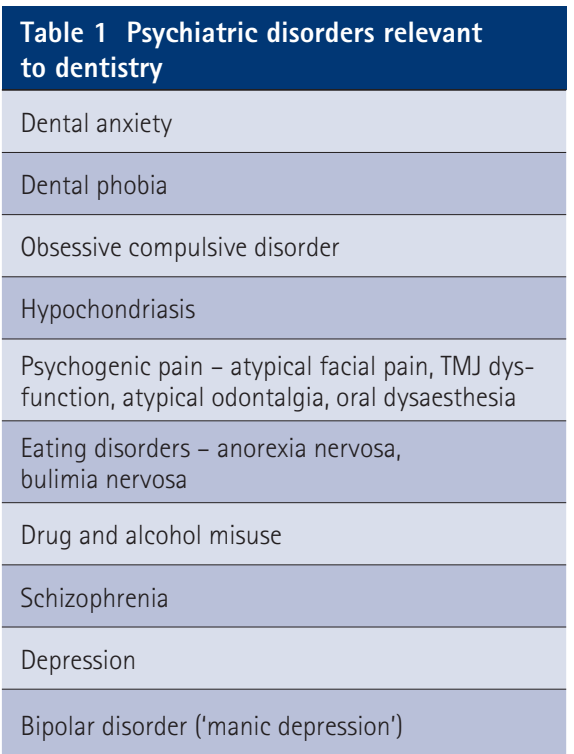

diagnosis. The symptoms discussed here may occur as features of a number of different physical and psychiatric conditions, or at times be an appropriate response to a situation.

\section{Anxiety}

Anxiety can be a normal response to perceived danger, activating the sympathetic nervous system in the performance enhancing response commonly known as 'fight or flight'. If anxiety becomes too intense, frequent or persistent and interferes with daily life, it may be considered pathological and part of an anxiety disorder.

Certain circumstances will induce a 'state' of anxiety in all of us. Some people are naturally more anxious than others, however, with a high level of 'trait' anxiety, and may be predisposed to anxiety disorders. Anxiety symptoms may be 
physical or psychological (Table 2) and may be so severe the individual attempts to avoid all possible triggers, potentially restricting their lifestyle significantly.

of particular interest to the dentist is dental anxiety. Some estimates suggest up to $90 \%$ of people experience significant levels of anxiety before visiting the dentist, with 40\% of adults delaying or completely avoiding visits because of anxiety. This may be highly specific amounting to odontophobia, or be a feature of generalised anxiety disorder. Anxious patients may not tolerate dental procedures without prior measures to reduce their anxiety and may find it difficult to pay attention to questions or advice, leading to difficulties in communication.

A recent study ${ }^{2}$ reported that in addition to apprehension about injections, common fears were seeing, hearing and feeling the vibrations of a dental drill. Specific questionnaires such as the Corah anxiety scale ${ }^{3,4}$ are available to assess anxiety. These are not employed by many British dentists but are more likely to be used by practitioners providing intravenous sedation. ${ }^{5}$ Management of anxiety need not necessarily include medication, though anxiolytics such as benzodiazepines may be beneficial in the short-term. Nonmedical interventions of benefit include cognitive behavioural therapy. Ideally steps should be taken to avoid the development of dental anxiety in the first instance, particularly for children. Simple measures aimed at making the dental consultation a pleasant experience may be invaluable, with judicious use of lighting and music and perhaps adjusting one's attire.

\section{Paranoia}

Meaning literally 'outside the mind', this term describes extreme suspiciousness or mistrust without reason. It may be a symptom of a number of disorders, including paranoid schizophrenia, psychotic depression, mania or drug and alcohol misuse. It may also be a feature of dementia, or simply a personality trait which may or may not be part of a personality disorder. In all these conditions paranoia may be associated with hallucinations in any modality, as well as changes in behaviour and cognitive function.

A paranoid patient may, like a dental phobic, avoid the dentist altogether.

\section{Table 2 Symptoms of anxiety}

\begin{tabular}{l|l} 
Psychological & Physical \\
$\begin{array}{l}\text { Worry } \\
\text { Sense of dread } \\
\text { Irritability } \\
\begin{array}{l}\text { Poor concentration } \\
\text { Restlessness }\end{array}\end{array}$ & $\begin{array}{l}\text { Gastrointestinal: dry mouth, nausea, swallowing difficulties, } \\
\text { disturbance of bowel habit } \\
\text { Cardiovascular/Respiratory: shortness of breath, chest pain, } \\
\text { palpitations, tachycardia } \\
\text { Neuromuscular: headache, light-headedness, weakness, 'jelly legs', } \\
\text { tremor, muscle aches } \\
\text { Other: sweating }\end{array}$ \\
\hline
\end{tabular}

\section{Table 3 Core features of depression}

\begin{tabular}{l|l}
\hline $\begin{array}{r}\text { Core features of depression } \\
\text { Depressed mood: most days } \\
\text { for most of day } \\
\text { for two weeks or more }\end{array}$ & $\begin{array}{l}\text { Additional features } \\
\text { Poor appetite and weight loss } \\
\text { Sleep disturbance }\end{array}$ \\
\hline Lack of energy (anergia) & Poor concentration \\
\hline Loss of enjoyment (anhedonia) & Psychomotor retardation or agitation \\
\hline Hopelessness and suicidal ideation & Feelings of guilt and worthlessness \\
\hline Loss of libido & \\
\hline $\begin{array}{l}\text { Delusions and hallucinations if severe } \\
\text { (guilt, worthlessness, poverty or disease) }\end{array}$ & \\
\hline
\end{tabular}

Alternatively paranoia may lead to mistrust of the dentist's advice, complaints against the dentist, or seeking repeated consultations with different practitioners.

\section{Depression}

A lowering of mood may be a feature of many illnesses, or a side-effect of many common medications (eg Beta blockers). When severe enough to affect daily life and associated with symptoms such as disturbance of sleep, appetite and reduced enjoyment of usual activities, it may be part of a syndrome of clinical depression (Table 3). Depressive illness is very common, affecting up to $10 \%$ of men and $20 \%$ of women at some point in their lives.

The dentist may find such patients slow to answer questions, make decisions or grasp advice given and might easily feel frustrated with their negativity or avoidance of eye contact. They may also have lower tolerance for pain or discomfort associated with dental conditions or treatment.

\section{Disinhibition}

This may be seen as part of a manic episode of bipolar disorder, or in patients with dementia or learning disability.

Bipolar affective disorder (manic depression) is characterised by discrete episodes of elevated mood (mania, or less severe hypomania) interspersed with episodes of either normal mood or periods of depressed mood. In an episode of elated mood, a patient may seem disinhibited either socially or sexually. They may be over-talkative, elated and excitable or agitated and at times dress or behave inappropriately. Concentration may be poor and patients may be unreliable historians. Although this is most likely to occur in the manic phase of bipolar disorder, alcohol, illicit drugs and occasionally prescribed medication such as steroids can cause a similar picture. Such a presentation could render dental intervention impossible during a particular visit, but is most likely to make the dentist uncomfortable; a chaperone is thus advisable at all times in the interests of both dentist and patient.

\section{Hyperactivity}

Extreme restlessness may be a side-effect of certain psychiatric drugs or a feature of stimulant drug use. Hyperactivity is most likely to be seen in children with attention deficit hyperactivity disorder (ADHD) and its variants. It may be particularly difficult to examine an overactive child and the environment of the dental surgery may prove hazardous. As with all children's consultations, if an examination is 
essential it may be useful to try to simplify the environment as much as possible in advance. Simple calming measures such as softer lighting and music, or projecting something to capture the child's attention on the ceiling may prove useful.

\section{THE DENTIST MAY DETECT A PSYCHIATRIC ILLNESS}

Some psychiatric disorders have significant dental signs and symptoms and may thus be noted for the first time in a dental consultation. This includes eating disorders, pain syndromes, use of certain illicit drugs and occasionally psychosis.

\section{Eating disorders}

Induced vomiting may be a feature of either anorexia nervosa or bulimia nervosa, leading to some specific signs pertinent to the dentist. Erosion of the dental enamel, especially on the palatal surfaces, may be caused by exposure to gastric acid in vomiting. This may be associated with callusing on the dorsum of the fingers (Russell's sign). In addition to affecting the dental hard tissues, eating disorders may be the cause of mucosal lesions such as erythema, periodontitis and salivary hypofunction. ${ }^{6}$ As well as symptoms of malnutrition and vitamin deficiency there may be profound disturbances of electrolytes, particularly potassium, which can lead to fatal arrhythmias.

\section{Pain syndromes}

Up to 50\% of psychogenic pain is experienced as occurring in the head. There are four major recognised syndromes: atypical facial pain, temporomandibular joint dysfunction syndrome (TMD) (facial arthromyalgia), atypical odontalgia and oral dysaesthesia. It can be difficult to distinguish between true pain of dental origin, for which a dental intervention may be appropriate, and psychogenic pain, particularly as the experience for the patient is as for real pain. Certain clues in the history may suggest a psychological origin, however, and these are summarised in Table 4.

\section{Hypochondriasis}

Occasionally the dentist may see a patient convinced of the presence of an underlying disease, despite an absence of physical signs or positive investigations. Multiple minor symptoms may be presented as evidence and these should be taken seriously, with relevant examination and investigations undertaken to exclude physical disease. If hypochondriasis is suspected, however, it is advisable to seek psychiatric help at an early stage, as prolonged investigations and repeated assessments will reinforce the illness beliefs and may in fact exacerbate the condition.

\section{Substance misuse}

It is not only one's patients who are at risk of substance misuse - drug and alcohol problems are high among medical and dental professionals. ${ }^{7}$ It is therefore worth being alert to the signs of problematic substance use which, untreated, can be devastating on a personal, social and professional level.

Misuse of drugs can cause many orodental manifestations and interfere with dental management. ${ }^{8}$ A few examples are given here.

Dental consequences of misuse of the stimulant methamphetamine may include xerostomia, bruxism (which can lead to TMD), self-neglect and a rapidly deteriorating, advanced state of dental decay known as 'meth mouth'?

Cocaine use can cause problems that may present to the dentist in the absence of overt dental pathology. Pain in the teeth and gums is a recognised feature of cocaine abuse and may be due to teeth grinding and jaw-clenching. The localised
Table 4 Features suggestive of psychogenic pain

Inconsistency with known anatomical landmarks/nerve distribution

\begin{tabular}{|l|}
\hline Bilateral \\
\hline Continuous with little fluctuation \\
\hline $\begin{array}{l}\text { May prevent falling asleep but does not wake } \\
\text { the patient up }\end{array}$ \\
\hline History of repeated negative investigations \\
\hline Analgesia has a very limited effect \\
\hline Association with emotional factors \\
\hline $\begin{array}{l}\text { Nature of the pain may have a symbolic } \\
\text { significance for the patient }\end{array}$ \\
\hline
\end{tabular}

vasoconstriction produced by cocaine can cause gingival necrosis if this area is used by abusers to test the 'quality' of the drug.

Benzodiazepine withdrawal may cause a characteristic syndrome of paraesthesia, hypersensitivity and pain in the teeth or jaw in almost 50\% of patients who try to stop or reduce these drugs, making a reduction in long-term use problematic. Similar problems may occur with opiate withdrawal.

\section{Psychosis - (hallucinations and delusions)}

Sometimes paranoia may take the form of a delusion - a fixed belief that persists despite evidence to the contrary and is at odds with the individual's culture, religion

\begin{tabular}{|c|c|}
\hline Drug type & Interactions \\
\hline $\begin{array}{l}\text { Antidepressants: } \\
\text { Tricyclics (amitriptyline, clomipramine, } \\
\text { imipramine, trimipramine, lofepramine) }\end{array}$ & $\begin{array}{l}\text { Local anaesthetic: sympathomimetics (eg adrena- } \\
\text { line) } \rightarrow \text { hypertension and arrhythmias - not a contra-indi- } \\
\text { cation to adrenaline but dose reduction is advised } \\
\text { General anaesthetic }(\mathrm{GA}) \rightarrow \text { increased risk of cardiac } \\
\text { arrhythmias and hypotension }\end{array}$ \\
\hline $\begin{array}{l}\text { MAOIs (monoamine-oxidase inhibitors, } \\
\text { eg phenelzine }\end{array}$ & $\begin{array}{l}\mathrm{GA} \rightarrow \text { hypertension and arrhythmias } \\
\text { Risk of hypertensive crisis - MAOI should be stopped two } \\
\text { weeks before anaesthetic }\end{array}$ \\
\hline $\begin{array}{l}\text { Mood stabilisers: } \\
\text { Lithium }\end{array}$ & $\begin{array}{l}\text { Antibiotics, particularly metronidazole, may cause } \\
\text { lithium toxicity } \\
\text { NSAIDS, eg ibuprofen, diclofenac may cause lithium toxicity } \\
\text { GA } \rightarrow \text { enhanced hypotensive effect }\end{array}$ \\
\hline Antipsychotics & $\begin{array}{l}\text { Antibiotics } \\
\text { Erythromycin } \rightarrow \text { increased risk of convulsions with } \\
\text { clozapine }\end{array}$ \\
\hline Dementia drugs & Ketamine $\rightarrow$ toxic combination with memantine \\
\hline ADHD drugs & $\mathrm{GA} \rightarrow$ hypertension with methylphenidate \\
\hline
\end{tabular}


and circumstances. This may occur in psychotic depression or schizophrenia as well as mania or drug use.

An example of relevance to the dentist might be a patient complaining of pain or requesting an extraction in the belief that a transmitter has been implanted in a tooth.

\section{DENTAL COMPLICATIONS OF PSYCHIATRIC ILLNESS}

Oral dystonias, drooling and bruxism may be the extrapyramidal side-effects of a number of drugs used to treat psychiatric illness, primarily the older (but still used) 'typical' antipsychotics such as haloperidol, chlorpromazine, and most slow-release 'depot' medications. These, and the drugs commonly used to counter such side-effects, also have anticholinergic properties and may cause a dry mouth. Potential interactions with psychiatric drugs are summarised in Table 5.

Poor oral hygiene and general self-care may occur in chronic mental illness, resulting in advanced dental caries or infection with late presentation to the dentist. This may also occur in dementia and people with learning disabilities, occasionally requiring multiple extractions or total dental clearance.

\section{PSYCHIATRIC ILLNESS PRESENT BUT UNRELATED TO DENTAL PROBLEMS}

In many cases the presence of psychiatric illness may be of no relevance to dental management, particularly for routine work. Nonetheless it can be useful to have some understanding of certain conditions and in particular the drugs used to treat them.

\section{Dementia}

Dementia is defined as an acquired impairment of global cognitive function, which is generally progressive and largely irreversible. It is a disorder which is of relevance to most healthcare professionals. Alzheimer's disease is the most common cause of dementia, with a prevalence increasing significantly with age. Approximately $1 \%$ of 65 -year-olds, 5\% of 75-year-olds and 20\% of 85-year-olds are affected..$^{10}$ Vascular dementia due to atherosclerosis is also common though there are also several other types of dementia.

\section{Table 6 CAGE questionnaire}

\begin{tabular}{l|l} 
C: & Have you ever felt you should Cut down the amount you drink? \\
\hline A: & Are you Annoyed if people comment upon the amount you are drinking? \\
\hline G: & Do you ever feel Guilty about the amount you are drinking \\
\hline E: & Have you ever had a drink early in the morning as an 'Eye-opener'?
\end{tabular}

\section{Table 7 Mental state examination}

\begin{tabular}{|c|c|}
\hline Appearance and behaviour & $\begin{array}{l}\text { How are they dressed? Are they clean? Shaven? Well-groomed? } \\
\text { Or dishevelled and unkempt or flamboyantly or scantily dressed } \\
\text { for the weather? Still in their pyjamas or slippers? } \\
\text { Do they seem withdrawn or slowed down? Overactive or intrusive? } \\
\text { Jumpy or on-edge? Are they aggressive? Are there any notable } \\
\text { mannerisms or unusual movements? }\end{array}$ \\
\hline Speech & $\begin{array}{l}\text { Fast or slow, quiet or loud, monotonous, repetitive, } \\
\text { slurred or stuttering? }\end{array}$ \\
\hline Thoughts & $\begin{array}{l}\text { Form - are they in an ordered flow, or disordered, fragmented } \\
\text { and disconnected? } \\
\text { Content - is there a particular preoccupation? Are there } \\
\text { unusual beliefs which are held firmly and may not be based } \\
\text { in reality (delusions)? }\end{array}$ \\
\hline Mood & $\begin{array}{l}\text { Objective (practitioner's view) and subjective (the patient's view) - } \\
\text { elated, depressed, neither? } \\
\text { Reactivity - is there an emotional response to sad or funny material? } \\
\text { Is the response as would be expected? }\end{array}$ \\
\hline Abnormal sensory experiences & $\begin{array}{l}\text { Hallucinations - do they seem to be responding to sensory stimuli } \\
\text { which cannot be detected? Or are there misperceptions of stimuli? }\end{array}$ \\
\hline Cognitive functioning & $\begin{array}{l}\text { Orientation - do they know where they are in time and place } \\
\text { and who they are? } \\
\text { Memory - can they recall how they got there? Can they recall their } \\
\text { last appointment, or what advice they received? } \\
\text { Concentration - are they following discussion? Where is their } \\
\text { attention? Poor concentration may make memory seem impaired. }\end{array}$ \\
\hline Insight & $\begin{array}{l}\text { Do they recognise there is a problem? Do they understand it? Are they } \\
\text { willing to receive help or treatment? }\end{array}$ \\
\hline
\end{tabular}

The patient in the early stages of dementia may not seem cognitively impaired, but may struggle to take in new information and may therefore not follow the dentist's advice. In cases of more advanced dementia the disability will be obvious and it may be a challenge to persuade the patient to co-operate with a dental examination. In both cases dental pain or the presence of infection may significantly exacerbate any cognitive impairment or confusion and swift treatment can lead to dramatic improvements in function.

\section{Learning disability}

'Learning disability' is the term used to describe the presence of an intellectual deficit present from childhood.

It should be remembered that although a carer may seem to speak for patients with cognitive impairments, under the Mental
Capacity Act (2005) all individuals over 16 years of age are presumed to have capacity unless proven otherwise. Consent should thus always be sought from the patient regardless of the apparent extent of their impairment.

\section{THE DENTAL PROFESSIONAL MAY BE AFFECTED BY A MENTAL ILLNESS}

Most common conditions have already been mentioned; depression (see above) and alcohol misuse are perhaps the most relevant in this scenario.

\section{Alcohol}

Alcohol abuse may be suspected if the individual smells of alcohol or has a tremor, which could be due to withdrawal. Attention should be paid to the time of day, as those with alcohol dependence may 
drink early in the morning to overcome withdrawal phenomena. The CAGE questionnaire (Table 6) is a simple and useful screening tool to detect alcohol dependency. Patients scoring 2 or more are highly likely to have alcohol problems but a negative CAGE response does not rule out alcohol misuse.

\section{CAPACITY AND CONSENT}

It is easy to assume that patients suffering from significant psychiatric illnesses, dementia, learning disability or other impairments may not have the capacity to make their own decisions about treatment or to give consent; indeed dentists may at times find themselves under pressure from relatives and carers to accept their decisions made on behalf of a patient.

The Mental Capacity Act (2005) ${ }^{11}$ (introduced into practice in 2007) is an important piece of legislation designed to protect the rights of individuals to make their own decisions and provides guidelines to address this. It sets out guidance for decision-making on behalf of people who lack decisionmaking capacity and applies to all people aged 16 and over in England and Wales.

Decision-making capacity is considered to be task-specific, relevant only to a specific decision at a given time and should not be generalised to other situations and decisions.

There are five basic principles:

- Autonomy: presumption of capacity. People are presumed to have capacity until proven otherwise

- Decision-making capacity must be maximised by all practicable means

- An individual has the right to make an unwise decision

- Best interests: decisions or acts taken on behalf of a person who is found to lack capacity must be taken in their best interests

- Least restrictive: the least restrictive decision or action should be taken, where an individual is found to lack decision-making capacity.

Capacity should be assessed by the person who is proposing treatment and seeking consent, using a standard two part question:

1. Is there an impairment of, or a disturbance in the functioning of, the mind or brain?
2. If so, does its presence impair the person's ability to make a particular decision?

A four-stage test adapted from common law must then be applied, looking at the decision-making process itself:

'A person is unable to make a decision for himself if he/she is unable-

(a) To understand the information relevant to the decision

(b) To retain that information (for at least long enough to make the decision)

(c) To use or weigh that information as part of the process of making the decision, or

(d) To communicate his/her decision (whether by talking, using sign language or any other means).'

Relevant information should be provided in a manner appropriate to the needs of the patient, involving an interpreter where necessary, and the patient should be similarly aided in communicating his/her decision. There is also a requirement to attempt to determine whether a lasting power of attorney (LPA) exists, appointing someone to act on their behalf in relation to health and welfare decisions.

If an individual is found to be lacking the capacity to make a particular decision, there are two possible courses of action - either to defer treatment and reassess, or to act in 'best interests'. 'Best interests' must be determined on an individual basis, taking into account all possible sources of information and may require the involvement of an independent mental capacity advocate (IMCA). The Act contains guidance for doing this.

Further information is contained within the Mental Capacity Act and its Code of Practice, and guidance is freely available for healthcare professionals through organisations such as the British Medical Association. ${ }^{12}$

\section{WHAT TO DO WHEN PROBLEMS ARISE}

There are no hard and fast rules about who should or should not be referred for further assessment. A number of scenarios may arise in dental practice:

- New presentation of psychiatric illness - such patients should be encouraged to speak to their general medical practitioner (GMP) about whatever symptoms have been noticed. It is not necessary to suggest it may be due to psychiatric illness

- Deterioration of existing illness these patients should be asked to speak to their GMP or existing psychiatric services

- Overt suicidal ideation (either as new or altered presentation) - such patients should be advised to speak to their GMP or go to ActE, or the on-call psychiatric services or police should be contacted directly

- Patient presenting an immediate danger to others - call the police

- You or a colleague need help - a GMP or ActE should be able to help, or contact the confidential Dentists' Health Support Programme.

\section{PSYCHIATRIC ASSESSMENT}

As with all assessments, the psychiatric history focuses on the presenting complaint, followed by detailed contextual information including previous psychiatric problems, physical health problems, medication and a detailed developmental, personal and social history. A physical examination remains relevant and can reveal many clues as to the source of the psychiatric symptoms (eg hyper- or hypothyroidism, needle-tracks from injection of illicit drugs, neurological abnormalities). The main difference in a psychiatric assessment is the mental state examination, which requires careful observation of the patient and provides valuable clues as to which diagnosis should be reached (Table 7), and the risk assessment.

\section{Risk assessment}

Contrary to what the media would have us believe, patients with psychiatric illness are rarely a risk to others. Around 5\% of all homicides are committed by people with a diagnosis of schizophrenia. Drug or alcohol abuse, however, are thought to contribute to over half of all murders. Far more likely is the risk to self, either through self-neglect due to illness, selfharm or suicide. While the best predictor of future behaviour is past behaviour, there are also a number of risk factors recognised to increase the likelihood of suicide, not all of which may be modified. Some of these are summarised in Table 8. 
Along with doctors and lawyers, dentists are recognised as a group of professionals at a high risk of mental health problems including drug and alcohol misuse and suicide. Recognising and understanding problems in oneself or in colleagues may be just as important as recognising and understanding them in our patients.

\section{CONCLUSION}

Psychiatric problems are common and are likely to be encountered in routine dental practice. Many disorders have common symptoms that may be managed using the same general guiding principles, aiming to alleviate distress and anxiety, and respecting the individual's autonomy. Communication with carers may be important, as well as liaising with the patient's GMP or psychiatric services when necessary.

\section{Table 8 High risk characteristics for} suicide

Male $>$ Female

Age $>40$ years (increasing in young men)

Evidence of planning

Social classes I and V

Certain occupations: dentists, doctors, vets, lawyers

Unemployed

Living alone

Not married

Loss events: relationships, housing, finance

1. Crisp A H (ed). Every family in the land. London: Royal Society of Medicine Press, 2005.

2. Boyle C A, Newton T, Milgrom P. Who is referred for sedation for dentistry and why? Br Dent $J 2009$; 206: E12

3. Corah N L. Development of a dental anxiety scale.
J Dent Res 1969; 48: 596.

4. Corah N L, Gale E N, Illig S J. Assessment of a dental anxiety scale. J Am Dent Assoc 1978; 97: 816-819.

5. Dailey $Y$ M, Humphris G M, Lennon M A. Dental anxiety: the use of dental anxiety questionnaires: a survey of UK dental practitioners. Br Dent J 2001; 190: 450-453.

6. Russo L L, Campisi G, Di Fede O, Panzarella V, Muzio $L$ L. Oral manifestations of eating disorders: a critical review. Oral Dis 2008; 14: 479-484.

7. Newbury-Birch D, Lowry R J, Kamali F. The changing patterns of drinking, illicit drug use, stress, anxiety and depression in dental students in a UK dental school: a longitudinal study. Br Dent $J$ 2002; 192: 646-649.

8. Meechan J G. Drug abuse and dentistry. Dent Update 1999; 26: 182-190.

9. McGrath C, Chan B. Oral health sensations associated with illicit drug abuse. Br Dent J 2005; 198: 159-162.

10. Knapp M, Prince M, Albanese E et al. Dementia UK. The full report. London: The Alzheimer's Society, 2007.

11. Office of Public Sector Information. The Mental Capacity Act 2005. Available online at http://www. opsi.gov.uk/acts/acts2005/20050009.htm.

12. BMA Ethics. The Mental Capacity Act 2005. Guidance for health professionals. London: British Medical Association, 2009.

http://www.oma.org.uk/ethics/consent_and capacity/mencapact05.jsp. 